\title{
Similarities between Salmonella Enteritidis isolated from humans and captive wild animals in South Africa
}

\author{
Anthony M Smith ${ }^{1,2}$, Husna Ismail ${ }^{1,2}$, Maryke M Henton ${ }^{3}$, Karen H Keddy ${ }^{1,2}$, GERMS-SA Surveillance \\ Network \\ ${ }^{1}$ Centre for Enteric Diseases, National Institute for Communicable Diseases, Division in the National Health \\ Laboratory Service, Johannesburg, South Africa \\ ${ }^{2}$ Faculty of Health Sciences, University of the Witwatersrand, Johannesburg, South Africa \\ ${ }^{3}$ Idexx Laboratories, Johannesburg, South Africa
}

\begin{abstract}
Introduction: Salmonella is well recognized as an aetiological agent of gastrointestinal and diarrhoeal disease. Salmonella enterica serotype Enteritidis (Salmonella Enteritidis) is one of the commonest serotypes associated with foodborne illness. In South Africa, we compared Salmonella Enteritidis strains isolated from humans with gastroenteritis and strains isolated from captive wild animals, between June 2011 and July 2012.

Methodology: Bacteria were phenotypically characterized using standard microbiological techniques. Genotypic relatedness of isolates was investigated by pulsed-field gel electrophoresis (PFGE) analysis.

Results: a diversity of 27 PFGE patterns amongst 196 human non-invasive isolates was shown; two PFGE patterns predominated and accounted for $74 \%$ of all human isolates. Human isolates showed a $12 \%$ prevalence rate for nalidixic acid resistance. Animal isolates from 5 different sources were investigated. With the exception of an isolate from a ground hornbill, all animal isolates (jaguar, crocodile, lion and poultry) showed PFGE pattern matches to a human isolate. Animal isolates showed susceptibility to all antimicrobial agents tested, with the exception of nalidixic acid resistance in isolates from the lion and poultry source.

Conclusions: Our data showed similarities between Salmonella Enteritidis strains isolated from humans and captive wild animals, suggesting a probable common source for strains from humans and animals.
\end{abstract}

Key words: Salmonella Enteritidis; wild animal; pulsed-field gel electrophoresis; PFGE; PulseNet.

J Infect Dev Ctries 2014; 8(12):1615-1619. doi:10.3855/jidc.5393

(Received 06 June 2014 - Accepted 21 August 2014)

Copyright $(C 2014$ Smith et al. This is an open-access article distributed under the Creative Commons Attribution License, which permits unrestricted use, distribution, and reproduction in any medium, provided the original work is properly cited.

\section{Introduction}

Zoonotic diseases are caused by agents that are naturally transmissible between animals and humans. The majority ( $\sim 61 \%)$ of infectious organisms affecting humans are of a zoonotic nature [1]. Worldwide, foodborne zoonosis, and more especially diarrhoeal diseases, is an important cause of morbidity and mortality in humans [2,3]. Salmonella enterica is an important zoonotic bacterial pathogen and well recognised as an aetiological agent of gastrointestinal and diarrhoeal disease [4]. Non-typhoidal Salmonella (NTS) remains a primary cause of reported foodborne disease events worldwide and outbreaks involving this pathogen are commonly described [5]. Worldwide, the epidemiology of human Salmonella disease is dominated by only a few non-typhoidal serotypes [6]. In Africa, Salmonella enterica serotype Enteritidis (Salmonella Enteritidis) and Salmonella Typhimurium are the two most commonly reported serotypes of NTS $[7,8]$. In the developed world, NTS disease is usually a self-limiting gastroenteritis with low mortality in humans, however in sub-Saharan Africa, NTS also frequently causes invasive disease which is associated with a substantial burden of illness and death [9]. Salmonella Enteritidis has a particular affinity for events of foodborne illness. Surveillance for foodborne disease outbreaks in the United States of America in 2007, showed that amongst aetiological agents identified in outbreaks, Salmonella was the second most common bacterial agent identified, with Salmonella Enteritidis the most commonly identified serotype [10]. In the current study, we report on the similarities between Salmonella Enteritidis strains isolated from humans with gastroenteritis and strains isolated from captive wild animals in South Africa. 


\section{Methodology}

Study period and source of specimens/bacterial isolates

During the study period, June 2011 to July 2012, human bacterial isolates were investigated by the Centre for Enteric Diseases (CED) of the National Institute for Communicable Diseases. One hundred and ninety-six human isolates of Salmonella Enteritidis were investigated. The CED is a national reference centre in South Africa for human infections involving enteric pathogens, including: Salmonella species, Shigella species, diarrhoeagenic E. coli and Vibrio cholerae. The CED participates in national laboratory-based surveillance for these pathogens. Isolates are voluntarily submitted to the CED from $\sim 200$ clinical microbiology laboratories across the country. The CED is also the coordinating laboratory for the PulseNet Africa laboratory network (http://www.pulsenetinternational.org/networks/africa/ ). Animal specimens were investigated by Idexx Laboratories, Johannesburg, South Africa, which provides veterinary pathology laboratory services; bacterial isolates of zoonotic interest are, on an ad hoc basis, forwarded to the CED for genotyping and comparison to human isolates. Five animal isolates of Salmonella Enteritidis were investigated.

\section{Culture and identification of bacterial isolates}

Bacterial isolates were identified using standard phenotypic microbiological identification and serotyping techniques, briefly described as follows.
Specimens were cultured at $37^{\circ} \mathrm{C}$ on selective agar media and in enrichment broths (media were supplied by Diagnostic Media Products, National Health Laboratory Service, Johannesburg, South Africa and Selecta-Media, Johannesburg, South Africa); agar media included Tryptose Blood agar, MacConkey agar, Sorbitol-MacConkey agar, Xylose Lysine Deoxycholate agar and Deoxycholate Citrate agar; enrichment broths included Selenite-F Broth and Rappaport-Vassiliadis broth. Suspicious colonies cultured on agar media were further investigated and identified using the VITEK automated identification system (bioMérieux, Marcy-l'Étoile, France). Salmonella cultures were serotyped according to the White-Kauffmann-Le Minor scheme [11]. Antimicrobial susceptibility testing was performed on Mueller-Hinton agar (Diagnostic Media Products and Selecta-Media) using the Etest method (bioMérieux); the following antimicrobials were tested: ampicillin, augmentin, trimethoprim, sulfamethoxazole, chloramphenicol, nalidixic acid, ciprofloxacin, tetracycline, kanamycin, streptomycin, imipenem, ceftriaxone and ceftazidime. Minimum inhibitory concentration (MIC) breakpoint values (see footnotes in Table 1) as described by the Clinical Laboratory Standards Institute (CLSI) were used to define antimicrobial resistance [12].

\section{Genotyping of bacteria}

Genotypic relatedness of isolates was investigated by pulsed-field gel electrophoresis (PFGE) analysis of

Table 1. Summary of data for Salmonella Enteritidis isolated from animal species in South Africa

\begin{tabular}{|c|c|c|c|c|c|}
\hline $\begin{array}{c}\text { Type of animal } \\
\text { species }\end{array}$ & $\begin{array}{c}\text { Type or } \\
\text { source of } \\
\text { specimen } \\
\text { from animal } \\
\text { species } \\
\end{array}$ & $\begin{array}{l}\text { Symptoms of animal or } \\
\text { reason for specimen testing }\end{array}$ & $\begin{array}{c}\text { Province in } \\
\text { which specimen } \\
\text { was isolated }\end{array}$ & $\begin{array}{c}\text { Specimen } \\
\text { collection date }\end{array}$ & $\begin{array}{c}\text { Susceptibility to } \\
\text { antimicrobial agents } \\
\text { tested* }\end{array}$ \\
\hline $\begin{array}{c}\text { Crocodile } \\
\text { (Crocodylus } \\
\text { niloticus) }\end{array}$ & Liver & $\begin{array}{l}\text { Septicaemia in 6-month old } \\
\text { hatchlings }\end{array}$ & Mpumalanga & June 2012 & $\begin{array}{l}\text { Susceptible to all } \\
\text { antimicrobial agents }\end{array}$ \\
\hline $\begin{array}{c}\text { Jaguar (Panthera } \\
\text { onca) }\end{array}$ & Faeces & Diarrhoea & Gauteng & December 2011 & $\begin{array}{l}\text { Susceptible to all } \\
\text { antimicrobial agents }\end{array}$ \\
\hline $\begin{array}{c}\text { Poultry } \\
\text { (Galliformes) }\end{array}$ & $\begin{array}{l}\text { Peritoneal } \\
\text { swab }\end{array}$ & $\begin{array}{l}\text { Septicaemia and deaths in egg } \\
\text { laying hens }\end{array}$ & Limpopo & June 2012 & $\begin{array}{l}\text { Resistant only to } \\
\text { nalidixic acid }\end{array}$ \\
\hline
\end{tabular}


$X b a \mathrm{I}$ digested genomic DNA on a Bio-Rad CHEF-DR III electrophoresis system (Bio-Rad Laboratories, Hercules, USA) using a PulseNet protocol [13]. PFGE patterns were captured into the PulseNet Africa database and analyzed using BioNumerics (version 6.5) Software (Applied Maths, Sint-Martens-Latem, Belgium) with dendrograms of the patterns created using the unweighted pair group method with arithmetic averages, with analysis of banding patterns incorporating the Dice-coefficient at an optimization setting of $1.5 \%$ and a position tolerance setting of $1.5 \%$.

\section{Results and Discussion}

Salmonella Enteritidis and Salmonella Typhimurium are the two most commonly reported serotypes of NTS in humans in South Africa [14]. CED surveillance data for the years 2009-2011 showed that Salmonella Enteritidis and Salmonella Typhimurium accounted for 55\% (3500/6345) of all Salmonella isolates tested; Salmonella Enteritidis alone accounted for 25\% (1578/6345). Our human Salmonella Enteritidis PFGE database was established in June 2011 and includes only non-invasive (mostly from stool) isolates. For the period June 2011 to July 2012; 196 human non-invasive isolates were analyzed and they showed 27 unique patterns (Figure 1). Two predominant patterns (pattern 6 and pattern 14) were found to exist and accounted for $74 \%$ of all human isolates; pattern 6 was represented by 89 human isolates, while pattern 14 represented 55 human isolates. Salmonella Enteritidis is often described as a highly clonal serotype and as a result, some studies have reported how commonly used subtyping methodologies (including PFGE) may sometimes lack the discriminatory power to partition Salmonella Enteritidis strains into epidemiologically meaningful clusters. Our current study showed a good diversity of 27 PFGE patterns amongst 196 human isolates tested, suggesting that PFGE may still be a useful method for differentiating strains of Salmonella Enteritidis, at least within the African setting. Furthermore, our 196 human non-invasive isolates showed a fairly low prevalence of resistance to antimicrobial agents, with $49 \%$ of isolates showing full susceptibility to all antimicrobials tested. Fewer than $2 \%$ of isolates showed resistance to ampicillin, augmentin, trimethoprim, chloramphenicol, ciprofloxacin, kanamycin, streptomycin, imipenem, ceftriaxone or ceftazidime. The following three antimicrobials were associated with higher prevalence of resistance in isolates: $43 \%$ for sulfamethoxazole, $12 \%$ for nalidixic acid and $4 \%$ for tetracycline. Nalidixic acid-resistant isolates all showed ciprofloxacin susceptibility (MICs, $0.125-0.25 \mu \mathrm{g} / \mathrm{ml})$.

Figure 1. PFGE patterns (XbaI digestion) for Salmonella Enteritidis isolated in South Africa

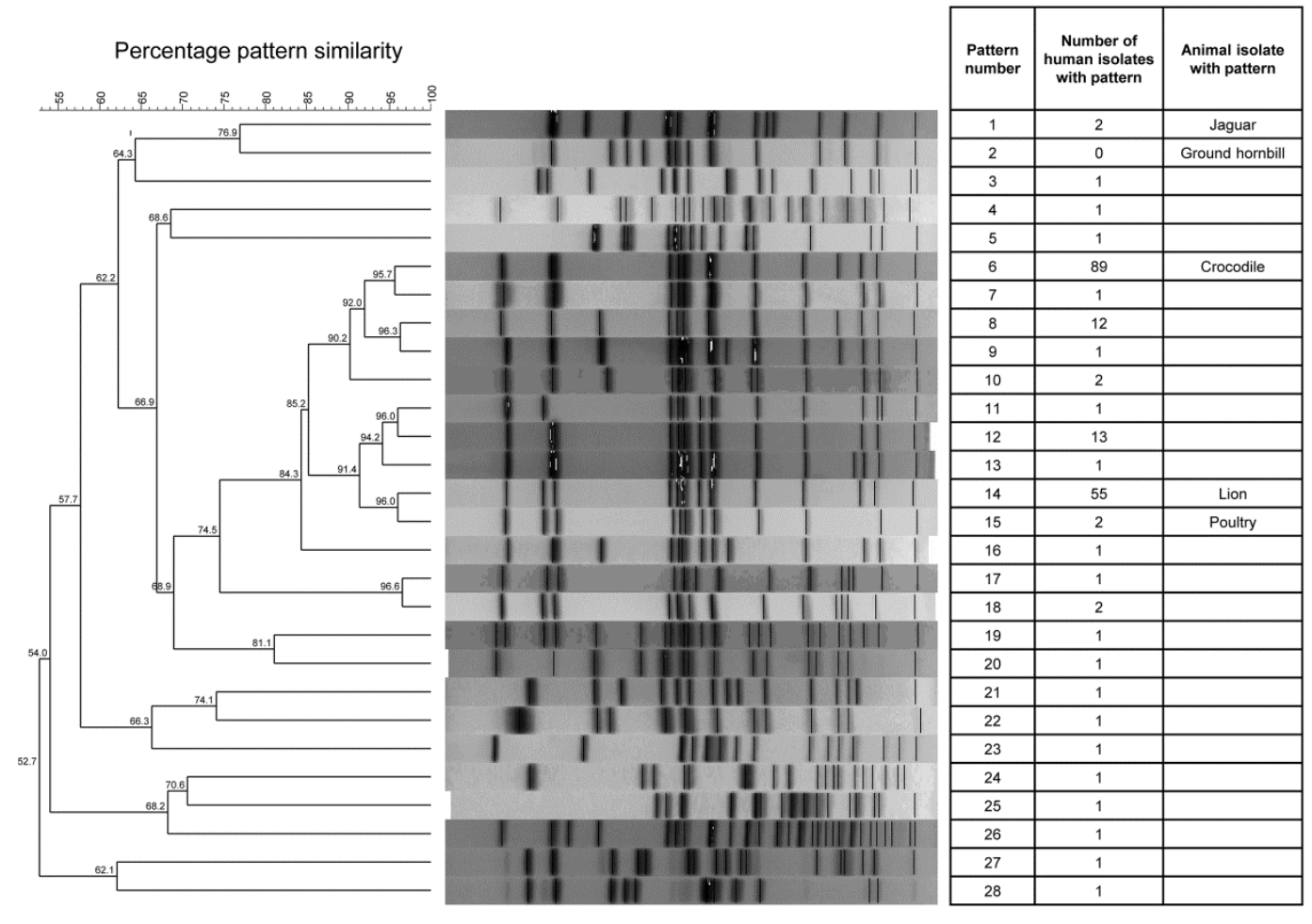


For the period June 2011 to July 2012, Idexx Laboratories in Johannesburg received $\sim 8000$ animal specimens for culture, of which 69 Salmonella enterica isolates were identified. Six isolates were serotyped as Salmonella Enteritidis; five isolates were available for further analysis. These five isolates were from different animal sources (Table 1) and included isolates from a jaguar (Panthera onca), a ground hornbill (Bucorvus leadbeateri), a crocodile (Crocodylus niloticus), a lion (Panthera leo), and a poultry source (Galliformes). There is no formalised surveillance system in place to investigate animal isolates; the CED receives animal isolates on an $a d$ hoc basis; this explains the small number of animal isolates investigated. Besides nalidixic acid resistance in isolates from the lion and poultry source, all animal isolates showed susceptibility to all antimicrobials tested. With the exception of the isolate from the ground hornbill, all animal isolates showed PFGE pattern matches to a human isolate (Figure 1). The PFGE pattern from the crocodile isolate matched PFGE pattern 6, the most commonly identified PFGE pattern from human isolates. PFGE patterns of isolates from the lion (pattern 14) and the poultry source (pattern 15) were extremely similar (96\% pattern similarity) and only differed by a single band; both these animal isolates also showed nalidixic acid resistance. PFGE pattern 14 is notably the second most commonly identified PFGE pattern associated with human isolates. For human isolates, of those showing PFGE pattern 14, 47\% (26/55) showed nalidixic acid resistance; while of those showing PFGE pattern 15 , $100 \%(2 / 2)$ showed nalidixic acid resistance.

Published data describing Salmonella isolated from captive wild animals is very limited, while data describing comparison of animal Salmonella isolates to human isolates is even more difficult to source; we were unable to find any data comparing genotypic data for Salmonella isolated from humans and captive wild animals. Amongst the limited published data on Salmonella isolated from captive wild animals, data on reptiles seems to be amongst the most commonly reported [15-18], including reports of Salmonella Enteritidis isolated from captive crocodiles [16]. Among animal species, Salmonella Enteritidis infections are largely associated with poultry. In South Africa, a study of Salmonella isolations from animal species showed that $96 \%$ of all Salmonella Enteritidis isolations originated from poultry [19]. Investigation of Salmonella Enteritidis outbreaks and sporadic cases regularly show that when human infections are identified as foodborne, then the most common sources of infection are poultry and poultry derivatives $[20,21]$. The diet of captive wild animals commonly includes poultry products such as chicken. Chicken products are widely available and a very affordable food source, especially for a carnivore diet which includes large volumes of meat. In South Africa, chicken meat is arguably the most affordable meat product for human consumption and as a result is a primary food source for humans. So, chicken meat and related chicken by-products may be a probable common link and may be a source of related strains of Salmonella Enteritidis isolated from humans and captive wild animals.

In conclusion, we show similarities between Salmonella Enteritidis strains isolated from humans with gastroenteritis and strains isolated from captive wild animals in South Africa, suggesting a probable common source for strains from humans and animals. A limitation of this study was the few animal strains investigated; this limitation can be overcome by establishing stronger links and networking between veterinary and human microbiology laboratories.

\section{Acknowledgements}

This work was financially supported by a grant received from the Medical Research Council, South Africa.

\section{References}

1. Christou L (2011) The global burden of bacterial and viral zoonotic infections. Clinical Microbiology and Infection 17: 326-330.

2. Newell DG, Koopmans M, Verhoef L, Duizer E, Aidara-Kane A, Sprong H, Opsteegh M, Langelaar M, Threfall J, Scheutz F, van der Giessen J, Kruse H (2010) Food-borne diseases the challenges of 20 years ago still persist while new ones continue to emerge. International Journal of Food Microbiology 139 Suppl 1, S3-S15.

3. Kuchenmuller T, Hird S, Stein C, Kramarz P, Nanda A, Havelaar AH (2009) Estimating the global burden of foodborne diseases - a collaborative effort. Eurosurveillance 14: 19195.

4. Majowicz SE, Musto J, Scallan E, Angulo FJ, Kirk M, O'Brien SJ, Jones TF, Fazil A, Hoekstra RM (2010) The global burden of nontyphoidal Salmonella gastroenteritis. Clin Infect Dis 50: 882-889.

5. Niehaus AJ, Apalata T, Coovadia YM, Smith AM, Moodley P (2011) An outbreak of foodborne salmonellosis in rural KwaZulu-Natal, South Africa. Foodborne Pathog Dis 8: 693697.

6. WHO Global Foodborne Infections Network Country Databank. Available: http://thor.dfvf.dk/portal/page?_pageid=53,46334\&_dad=port al\&_schema=PORTAL._Accessed 12 August 2014. 
7. Paglietti B, Falchi G, Mason P, Chitsatso O, Nair S, Gwanzura L, Uzzau S, Cappuccinelli P, Wain J, Rubino S (2013) Diversity among human non-typhoidal salmonellae isolates from Zimbabwe. Transactions of the Royal Society of Tropical Medicine and Hygiene 107: 487-492.

8. Kariuki S, Revathi G, Kariuki N, Kiiru J, Mwituria J, Muyodi J, Githinji JW, Kagendo D, Munyalo A, Hart CA (2006) Invasive multidrug-resistant non-typhoidal Salmonella infections in Africa: zoonotic or anthroponotic transmission? J Med Microbiol 55: 585-591.

9. Morpeth SC, Ramadhani HO, Crump JA (2009) Invasive nonTyphi Salmonella disease in Africa. Clinical Infectious Diseases 49: 606-611.

10. Morbidity and Mortality Weekly Report. (2010) Surveillance for foodborne disease outbreaks - United States, 2007. Morbidity and Mortality Weekly Report (MMWR) 59: 973979.

11. Grimont PAD, Weill FX (2007) Antigenic formulae of the Salmonella serovars (9th ed.). World Health Organization Collaborating Centre for Reference and Research on Salmonella, Institut Pasteur, Paris, France. Available: http://www.pasteur.fr/ip/portal/action/WebdriveActionEvent/ oid/01s-000036-089. Accessed 12 August 2014.

12. CLSI. Performance standards for antimicrobial susceptibility testing; twenty-fourth informational supplement. CLSI document M100-S24. Clinical and Laboratory Standards Institute, Wayne, Pennsylvania, USA, 2014.

13. Ribot EM, Fair MA, Gautom R, Cameron DN, Hunter SB, Swaminathan B, Barrett TJ (2006) Standardization of pulsedfield gel electrophoresis protocols for the subtyping of Escherichia coli O157:H7, Salmonella, and Shigella for PulseNet. Foodborne Pathog Dis 3: 59-67.

14. GERMS-SA Surveillance Network. Annual Report 2012. Available: http://www.nicd.ac.za/assets/files/2012_GERMSSA_Annual_Report.pdf. Accessed 12 August 2014.

15. Gopee NV, Adesiyun AA, Caesar K (2000) Retrospective and longitudinal study of salmonellosis in captive wildlife in Trinidad. Journal of Wildlife Diseases 36: 284-293.

16. Manolis SC, Webb GJ, Pinch D, Melville L, Hollis G (1991) Salmonella in captive crocodiles (Crocodylus johnstoni and C. porosus). Australian Veterinary Journal 68: 102-105.
17. Silva-Hidalgo G, Ortiz-Navarrete VF, Alpuche-Aranda CM, Rendon-Maldonado JG, Lopez-Valenzuela M, JuarezBarranco F, Lopez-Moreno HS (2012) Non-typhi Salmonella serovars found in Mexican zoo animals. Research in Veterinary Science 93: 1132-1135.

18. van der Walt ML, Huchzermeyer FW, Steyn HC (1997) Salmonella isolated from crocodiles and other reptiles during the period 1985-1994 in South Africa. Onderstepoort Journal of Veterinary Research 64: 277-283.

19. Kidanemariam A, Engelbrecht M, Picard J (2010) Retrospective study on the incidence of Salmonella isolations in animals in South Africa, 1996 to 2006. Journal of the South African Veterinary Association 81: 37-44.

20. Nesbitt A, Ravel A, Murray R, McCormick R, Savelli C, Finley R, Parmley J, Agunos A, Majowicz SE, Gilmour M (2012) Integrated surveillance and potential sources of Salmonella Enteritidis in human cases in Canada from 2003 to 2009. Epidemiology \& Infection 140: 1757-1772.

21. Kimura AC, Reddy V, Marcus R, Cieslak PR, Mohle-Boetani JC, Kassenborg HD, Segler SD, Hardnett FP, Barrett T, Swerdlow DL (2004) Chicken consumption is a newly identified risk factor for sporadic Salmonella enterica serotype Enteritidis infections in the United States: a casecontrol study in FoodNet sites. Clinical Infectious Diseases 38 Suppl 3, S244-S252.

\section{Corresponding author}

Dr Anthony Smith

Centre for Enteric Diseases, National Institute for Communicable Diseases, Private Bag X4, Sandringham, 2131, Gauteng, South

Africa

Phone: +27-11-5550348

Fax: +27-11-5550433

Email: anthonys@nicd.ac.za

Conflict of interests: No conflict of interests is declared. 